\title{
Puxando os fios do emaranhado pré-natal: gênero, biomedicina e a biopolítica da maternidade
}

\author{
Unraveling the entanglement of prenatal care: gender, \\ biomedicine, and the biopolicy of motherhood
}

\author{
Tirando de los hilos de la maraña prenatal: género, \\ biomedicina y biopolítica de la maternidad
}

TANGLED DIAGNOSES: PRENATAL TESTING, WOMEN, AND RISK. Löwy I. Chicago/London: University of Chicago Press; 2018. 319 p. ISBN 978-0-226-53412-1.

doi: 10.1590/0102-311X00133818

Em seu livro Tangled Diagnoses: Prenatal Testing, Women, and Risk, Ilana Löwy analisa as consequências materiais, sociais e culturais da introdução de uma importante inovação do campo biomédico: os testes diagnósticos pré-natais. Löwy encara esses testes como um dispositivo, isto é, um conjunto altamente heterogêneo de técnicas e abordagens de gerenciamento de riscos que, combinadas, possibilitam o escrutínio de fetos. Além disso, encara-os também como uma tecnologia generificada, moldada por e inseparável das visões sobre o papel das mulheres na sociedade ocidental, vistas como "naturalmente" destinadas à maternidade e ao cuidado. Para a autora, embora não seja possível separar tal tecnologia das perspectivas culturais e sociais acerca do gênero e, especificamente, dos princípios que compõem a ideia de uma "boa mãe", essa discussão raramente integra os debates públicos sobre os usos dos testes diagnósticos pré-natais, sendo o livro um esforço de trazer à tona estas dimensões.

Löwy descreve que, a partir do final do século XIX, a medicina, visando a promover o nascimento de crianças saudáveis, amplificou a vigilância dos corpos das mulheres grávidas. Tal vigilância, denominada atenção pré-natal, foi intensificada a partir de meados do século XX. Atualmente, o dispositivo do teste diagnóstico pré-natal engloba dois conjuntos distintos de práticas: testes universalmente aceitos destinados a monitorar a saúde da mãe e do feto, e testes mais controversos, que tornam visíveis anomalias fetais.

Além dos avanços no campo da genética médica, é a ultrassonografia obstétrica - e a consequente visualização do feto durante a gestação uma das principais tecnologias que permite o desenvolvimento do dispositivo de teste diagnóstico pré-natal. Em seu trabalho sobre o ultrassom obstétrico no Brasil, Chazan 1 já apontava para a centralidade dessa tecnologia - transformada em objeto de desejo e consumo - na construção do feto como pessoa. Assim, a tecnologia do ultrassom articulada a novas abordagens diagnósticas produz uma nova entidade tecnocientífica: o feto "escrutinado".

Quase todas as mulheres grávidas, em países industrializados, passam por alguma forma de monitoramento e escrutínio do feto. Isso não é um ato sem consequências para a percepção e vivência da gravidez, podendo levar, implicitamente, à noção de que todo feto é malformado até que se prove o contrário, e de que cada mulher grávida é uma gestora racional de riscos. Embora os testes diagnósticos pré-natais permitam detectar malformações fetais, geralmente, não é possível ter certeza se a anomalia encontrada 
é isolada ou faz parte de alguma síndrome, ou ainda seu impacto na vida da futura criança. Diante de um resultado "suspeito" impõe-se um "balanceamento dos riscos", visto que nem tudo pode ser testado e nem tudo é inato, o que, com frequência, aumenta o estresse e a ansiedade da gestante, consequência pouco discutida do aumento dos testes diagnósticos pré-natais, conforme também observaram Corrêa \& Guilam 2.

No que diz respeito aos testes diagnósticos pré-natais, há uma significativa lacuna entre o aprimoramento das tecnologias diagnósticas e os tratamentos efetivamente disponíveis. A maior parte das condições detectadas durante a gestação não pode ser tratada ou curada e a única “solução" proposta, nos países em que o aborto é legalizado, é a interrupção da gravidez. Assim, a discussão sobre testes diagnósticos pré-natais é inseparável das discussões mais amplas sobre direitos reprodutivos e dos debates e controvérsias acerca do chamado "aborto seletivo".

O aborto seletivo é uma questão altamente polarizadora. A partir da década de 1980, o aborto de fetos com malformações adquiriu o rótulo de "eugênico", tendo como principais oponentes os ativistas "pró-vida" (opostos ao aborto em geral), um pequeno grupo de feministas, e ativistas dos direitos de pessoas com deficiências. O argumento principal desses últimos é que haveria uma diferença qualitativa entre aborto seletivo (refletindo a opção por uma criança considerada "normal" e a rejeição de uma deficiente) e a interrupção de uma gravidez indesejada. A polarização do debate, porém, mascara importantes questões, como as ambivalências das mulheres em relação a suas decisões reprodutivas e à centralidade da maternidade na identidade feminina.

O livro conjuga seis capítulos de densidades complementares, com rica historicização. Em $O$ Feto Liminal a autora discute o estado indeterminado e fluido dos fetos humanos, especialmente do "feto biomédico", entidade moldada por novas tecnologias biomédicas. No capítulo 2, Genética, Morfologia e Diagnósticos Difíceis, Löwy analisa os esforços para eliminar as incertezas dos testes diagnósticos pré-natais e a tentativa de se che- gar a resultados mais acurados, pela combinação de três abordagens: ultrassonografia obstétrica, análise do genoma fetal e fetopatologia.

Considerando que "os métodos empregados para investigar o feto são os mesmos em todos os países, mas seu uso é moldado por culturas médicas locais" (p. 13), Löwy investiga dois cenários distintos França e Brasil - e analisa os usos contextualizados desse dispositivo. Os capítulos 3 (Enigmas de Diagnóstico) e 4 (Desastres Visíveis) descrevem o trabalho de campo realizado em departamentos de fetopatologia de hospitais na França e no Brasil, respectivamente. A análise é marcada por uma grande diferença entre os países, que vai permear a prática dos médicos de cada local: a legalização do aborto na França e sua proibição no Brasil. No Brasil, o aborto só é permitido legalmente em casos de anencefalia. Gestantes cujos fetos possuam alguma anomalia grave podem tentar solicitar a um juiz permissão para interromper a gravidez, processo que não é simples ou garantido. A proibição do aborto, porém, não impede que ele seja realizado, evidenciando desigualdades de classe, já que apenas mulheres de camadas médias e altas podem pagar por abortos menos inseguros.

Löwy traça o debate atual sobre os testes diagnósticos pré-natais, chamando atenção para a pluralidade de atores como médicos, feministas, mulheres em geral e ativistas de movimentos de deficientes. O capítulo 5, Equilibrando Riscos, analisa as diferentes perspectivas e posicionamentos desses atores em torno do chamado aborto seletivo. Nesse cenário, os riscos estão relacionados a pelo menos três componentes: riscos para a saúde e bem-estar da criança e da família; riscos enfrentados por profissionais de saúde, que poderiam ser processados por diagnósticos errados, por exemplo; e riscos a serem equilibrados pela sociedade, com dimensões econômicas e sociais, especialmente em tempos de pressões para "normalizar" seres humanos, impedindo o nascimento daqueles cujos corpos seriam "desviantes".

A autora chama a atenção para uma grande “zona de silêncio” em torno dos testes diagnósti- 
cos pré-natais, já que aspectos "desconfortáveis" do uso desta tecnologia são, frequentemente, evitados. Em Diagnósticos Pré-natais, Escolhas Reprodutivas e Cuidados (capítulo 6), Löwy discute como mulheres equacionam possíveis riscos, quando cientes de condições hereditárias de suas famílias - uma abordagem preemptiva que, ao personalizar riscos, se ancora no pressuposto da vida como singularidade biológica, como aponta Castiel 3.

Fugindo de respostas fáceis e generalizações, Löwy não pretende eliminar dilemas produzidos pelo diagnóstico de anomalias fetais, ou acabar com controvérsias sobre reprodução e aborto seletivo. Este livro, em especial as conclusões, busca tornar compreensível diferentes perspectivas situadas e problemas concretos produzidos por essas tecnologias biomédicas - resultados falso-positivos e falso-negativos, a desgastante odisseia diagnóstica, o estresse produzido pela incerteza prognóstica, os aspectos materiais do aborto, o status liminar do feto e a ambivalência das mulheres sobre suas decisões reprodutivas. Löwy examina "cuidadosamente todos os seus aspectos, incluindo aqueles que geram desconforto, promovem visões inquietantes, que confrontam dificuldades" e "fica com o problema" (p. 222), como sugere Haraway 4 , sem tentar resolvê-lo ou simplificá-lo.

Para além das análises acadêmicas, a autora nos convida ainda a um belo diálogo com a arte para refletir sobre a questão. Na coda, $A$ Coruja de Minerva e a Lira de Apolo, Löwy justapõe duas obras de arte que lidam com a perda da gravidez. Valendo-se delas, a autora expõe as ambivalências em torno da maternidade, apontando que a arte pode alcançar outros modos de olhar para questões "desconhecidas conhecidas" (p. 231).

O livro traz discussões de interesse ao campo do gênero e saúde, apresentando questões que vão além dos usos de tecnologias. As consequências de seus usos, os impactos sociais e o que é possível pensar baseando-se nelas são apenas algumas das questões que os leitores encontrarão no livro. Em tempos de discussões polarizadas, Löwy nos mostra que há muito mais a desvendar entre o preto e o branco.
Marina Fisher Nucci 1

Fernanda Loureiro Silva 2

Andreza Rodrigues Nakano 3

1 Casa de Oswaldo Cruz, Fundação Oswaldo Cruz, Rio de Janeiro, Brasil.

2 Instituto de Medicina Social, Universidade do Estado do Rio de Janeiro, Rio de Janeiro, Brasil.

3 Escola de Enfermagem Anna Nery, Universidade Federal do Rio de Janeiro, Rio de Janeiro, Brasil.

marinanucci@gmail.com

1. Chazan L. "Meio Quilo de Gente": um estudo antropológico sobre ultra-som obstétrico. Rio de Janeiro: Editora Fiocruz; 2007.

2. Corrêa MCDV, Guilam MCR. O discurso do risco e o aconselhamento genético pré-natal. Cad Saúde Pública 2006; 22:2141-9.

3. Castiel LD. As fantasmagorias dos riscos à saúde e o presente do futuro. In: Oliveira C, Müller RF, organizadores. Subjetivações e gestão dos riscos na atualidade. Rio de Janeiro: Contra Capa/Fundação de Amparo à Pesquisa do Estado do Rio de Janeiro; 2017. p. 33-61.

4. Haraway D. Staying with the trouble: making Kin in the Chthulucene. Durham: Duke University Press; 2016. 